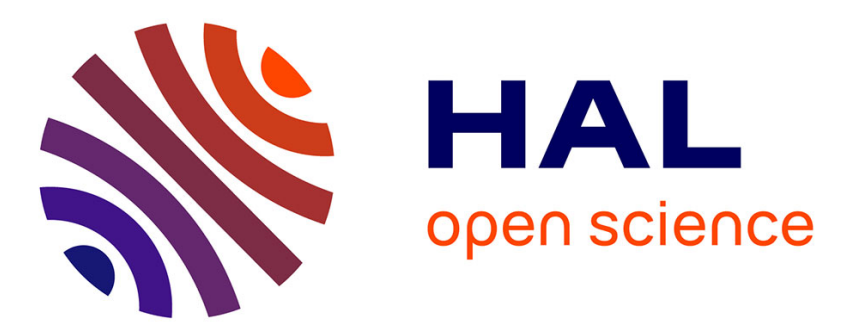

\title{
Network structural properties for cluster long run dynamics. Evidence from collaborative R\&D networks in the European mobile phone industry
}

Joan Crespo, Raphaël Suire, Jérôme Vicente

\section{- To cite this version:}

Joan Crespo, Raphaël Suire, Jérôme Vicente. Network structural properties for cluster long run dynamics. Evidence from collaborative R\&D networks in the European mobile phone industry. 2013. halshs-00911432

\section{HAL Id: halshs-00911432 \\ https://shs.hal.science/halshs-00911432}

Preprint submitted on 29 Nov 2013

HAL is a multi-disciplinary open access archive for the deposit and dissemination of scientific research documents, whether they are published or not. The documents may come from teaching and research institutions in France or abroad, or from public or private research centers.
L'archive ouverte pluridisciplinaire HAL, est destinée au dépôt et à la diffusion de documents scientifiques de niveau recherche, publiés ou non, émanant des établissements d'enseignement et de recherche français ou étrangers, des laboratoires publics ou privés. 


\section{Sciences Po Grenoble working paper n.5}

Network structural properties for cluster long run dynamics. Evidence from collaborative R\&D networks in the European mobile phone industry

Joan Crespo, LEREPS, University of Toulouse 1 Capitole

Raphaël Suire, CREM-CNRS, University of Rennes 1

Jérôme Vicente, Univ. Grenoble-Alpes, Sciences Po Grenoble, PACTE

November 2013

Partners //
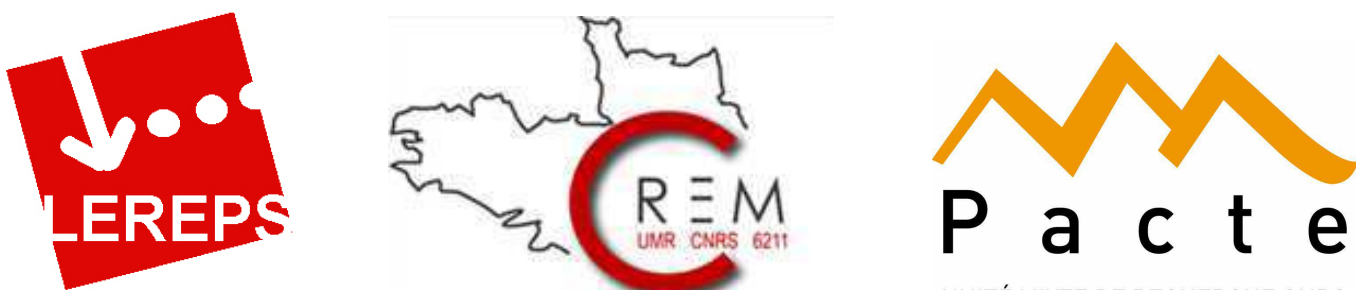


\title{
Network structural properties for cluster long run dynamics. Evidence from collaborative $R \& D$ networks in the European mobile phone industry
}

\author{
Joan Crespo ${ }^{1}$, Raphaël Suire ${ }^{2}$, and Jérôme Vicente ${ }^{1,3}$ \\ ${ }^{1}$ LEREPS, University of Toulouse \\ ${ }^{2}$ CREM-CNRS, University of Rennes I \\ ${ }^{3}$ PACTE-CNRS, Sciences-Po Grenoble
}

\begin{abstract}
In a recent literature, the structural properties of knowledge networks have been pointed out as a critical factor for cluster structural changes and long run dynamics. Mixing evolutionary economic geography and network-based approach of clusters, this contribution aims at capturing and discussing the particular influence of hierarchy (degree distribution) and assortativity (degree correlation) in the innovative capabilities of clusters along the industry life cycle. We test our propositions in the field of the mobile phone industry in Europe from 1988 to 2008. We use EPO PATSTAT and OECD REGPAT to capture cluster trends, and R\&D relations from European Framework Programs to capture knowledge networks and their evolving structural properties. Our findings provide new insights to understand the organization of clusters over time in order to perform along the industry life cycle
\end{abstract}

JEL codes: D85, L63, O33, R11

Acknowledgements: This research is supported by the Univeristy of Rennes 1 foundation and the "Open Research Area in Europe"' integrated project, funded by the ANR (France), DFG (Germany), ESRC (UK), and NWO (Netherlands) National Research Agencies. The authors are also grateful to Pierre-Alexandre Balland, Ron Boschma and Olivier Brossard for their constructive suggestions. 


\section{Introduction}

The literature has underlined the importance of networks for cluster performance, either to boost innovative capacities of clustered firms or to enhance firms formation and growth (Jaffe et al., 1993; Audretsch and Feldman, 1996b; Pouder and John, 1996; Buenstorf and Klepper, 2009). Porter (1998) already pointed to interaction and networks as one of the basic components of clusters, together with the co-location and the industrial dimensions. The current context featured by complex knowledge and rapid change has exacerbated the importance of networks. Innovation and knowledge creation are interactive processes (Nooteboom, 2000; Antonelli, 2005; Sorenson et al., 2006). Consequently, cluster innovative performance is strongly dependent on the capacity to host interacting organizations possessing and combining different and complementary competences and pieces of knowledge. In the policy sphere, these ideas have sustained the popularity of cluster policies to boost collaboration (Martin and Sunley, 2003). In the academia sphere, they have been strengthen by the current "relational turn" in economic geography (Bathelt and Glücker, 2003; Boggs and Rantisi, 2003), as well as the increasing availability of relational data and powerful analytic tools.

The convergence of these trends has produced an important bulk of studies trying to go beyond the treatment of networks as a metaphor. Researches form economy, sociology, management science and geography have tried to open the black box of networks by studying their formation, properties and evolution. This wave has structured around two interdependent questions. On the one hand, the decision of tie formation/disruption and the parameters behind partners selection (Jackson and Wolinsky, 1996; Ahuja, 2000; Rivera et al., 2010; Balland, 2012). On the other hand, the features of the relational structure emerging from the aggregation of individual relational decisions (Borgatti and Everett, 1999; Uzzi and Spiro, 2005; Vicente et al., 2011).

Network functioning is heterogeneous across/along industries and space. Literature on technological systems has shown that network tie formation and network structuring may differ across technologies or industries (Broekel and Graf, 2012), as well as along the technological or industrial cycle (Balland et al., 2013b; ter Wal and Boschma, 2011). Similarly, network functioning may be not independent of the geographical context. In that sense several papers have tried to identify both structural properties of networks in cities, clusters and regions favoring or hampering their innovative performance (Fleming et al., 2007; Breschi and Lenzi, 2012), and the features and behavior of actors in key positions in the structure (Giuliani and Bell, 2005; Morrison, 2008). The recent literature on cluster life cycles and regional resilience try to ally both of them to study how dissimilar network structures in particular locations perform differently by their capacity to associate or dissociate in the right moment of the technology life cycle (Suire and Vicente, 2009; Crespo et al., 2013).

The present chapter joins this literature. Our aim is to test the influence of two new structural properties of networks in cluster innovative performance: network hierarchy and network assortativity (Crespo et al., 2013). They complete small world (Watts and Strogatz, 1998) and core/periphery (Borgatti and Everett, 1999) structural measures at two levels. On the one hand, hierarchy introduces a structural measure of the existence (or not) of leading organizations able to coordinate systemic processes of innovation. On the other hand, assortativity introduces a measure of the structural openness, i.e. the connectivity between the core and the periphery that enhances the circulation of knowledge between both, favoring the arrival of new ideas. We test the influence of these two properties on the European mobile phone sector, which is characterized by standardization, modularity and rapidly shrinking 
product life cycles. Our results show that cluster innovative performance needs hierarchical and disassortative networks. This seems particularly important for industries where standardization processes and aggregation of complementary services are important, as it is the case in the mobile phone sector. Moreover, the important shock suffered by mobile phone sector in 2000 lets show that the influence of hierarchy and assortativity varies between growth and maturity industrial stages.

In the remainder of the chapter we proceed as follow: Section 2 develops the theoretical concepts we aim to test. It examines hierarchy and assortativity arguing why they matter for cluster innovative performance and elaborates the corresponding hypothesis. We discuss them with particular insights on the mobile phone sector in Europe. Section 3 presents the context of the analysis, the data collection process, the variables construction with particular detail on the two measures proposed for hierarchy and assortativity, and the estimated method used. In Section 4 we present the main results of the estimated models. Section 5 discusses the results on the context European mobile phone technological domain. Finally, Section 6 concludes.

\section{Network properties for cluster performance}

\subsection{Networks and clusters}

Taking a network perspective to approach cluster, we can define them as a set of local nodes (organizations) in a particular field, and the ties defined on them. Organizations in clusters have heterogeneous institutional forms, relational capacities and cognitive bases. They may construct relations of different nature (productive, commercial, cognitive or social) that work, primarily or subsidiary, as channels for voluntary or involuntary knowledge flows. The union of organizational and relational sets results in a network through which knowledge and information circulate more or less efficiently depending on its structural features.

The current context is featured by increased competition based on differentiation and rapid change. The continuous development of new products with an increasing number of complementary services and utilities drive the competition for the market (Moore, 1991). Organizations need to collaborate with others in order to get complementary pieces of knowledge and create differentiated products fast enough to be competitive. Consequently, the knowledge creation process becomes complex and composite (Nooteboom, 2000; Antonelli, 2005).

Atmoshere (Marshall, 1890), noise (Grabher, 2002) or buzz (Storper and Venables, 2004) are some of the concepts developed to underline the importance of co-location to gain access to valuable information and knowledge, voluntary or involuntary circulating locally. Thick local relational sets become the scaffolding for fast diffusion of knowledge that boosts innovative performance of clusters. Local organizations may also build up relations with organizations located elsewhere. Such distant relations, or pipelines, fill two functions. On the one hand, they give access to no-redundant ideas circulating elsewhere, and so as source of novelty, they may increase the innovative performance of the cluster (Uzzi, 1997). On the other hand, they are fundamental to embed the local cluster in a larger network that configures the global technological domain (Owen-Smith and Powell, 2004). The performance of the local environment and the global technological domain are mutually reinforcing (Bathelt et al., 2004).

However, networks are in permanent change. The process of network configuration is done by a successive and cumulative decisional process. Organizations chose their location (entry/exit 
decision). These are strategic decisions taken at a moment of time with a vocation to last give rise to the local set of nodes. Moreover, organizations chose their partners. Partnership construction is also strategic but much more fluid. So, organizations are continuously creating, maintaining or disrupting relations of different nature with other organizations. This self-organized process of organizations entry/exit and of relations formation/disruption produces a large diversity of structures not neutral for cluster innovative performance (Markusen, 1996; Cattani and Ferriani, 2008).

The link between innovation performance and the heterogeneity of network structures has produced several attempts to identify which network structural properties favor or hamper regional innovation performance. The most popular efforts concern small world networks (Kogut and Walker, 2001; Uzzi and Spiro, 2005; Fleming et al., 2007; Schilling and Phelps, 2007). They simultaneously exhibit high clustering and low average path length (Watts and Strogatz, 1998). The combination of these two properties is said to boost innovation. Clustering influences innovation because closure of networks generates trust (Granovetter, 1985; Coleman, 1988), and trust promotes collaboration and facilitates risk sharing, resource pooling and information diffusion. Low path length boosts innovation because it increases network connectivity, and so it makes easier knowledge circulation and transmission. Core/Periphery networks have also received important attention. They exhibit a group of organizations densely connected: the core; and a set of organizations loosely connected to it: the periphery (Borgatti and Everett, 1999). In this case, most of the studies have focused on differential performance between core and peripheral organizations, rather than in the influence of core/periphery structures in aggregate performance (regional or cluster). They argue that organizations in the core have a better access to knowledge flows (Giuliani and Bell, 2005) and higher survival rates (Mitchell and Singh, 1996). Such structures tend to be stable on time (Orsenigo et al., 1998) due to preferential attachment mechanisms (Barabási and Albert, 1999), and the influence of prior network structure in new ties formation (Gulati and Gargiulo, 1999). Thirdly, some authors have introduced the geographical dimension more explicitly to study the influence of network openness on performance, i.e. how the local structure of relations is embedded in a global context. They conclude that distant relations have a positive influence in regional innovative performance, because they bring new ideas into the region to avoid redundancy and lock-in (Bathelt et al., 2004; Breschi and Lenzi, 2012). In these structures the local organizations building distant relations, knowledge gatekeepers, have a prominent role for both cluster performance and vulnerability (Morrison, 2008; Hervás-Oliver and Albors, 2012). Recently, Crespo et al. (2013) have argued that hierarchy and assortativity of local networks matter for cluster performance. These structural properties account for the existence of a core/periphery structure, and for the features of the connexions between both. We develop both of them in the following sections.

\subsection{Hierarchy}

Organizations in clusters are heterogeneous at several levels. From a relational perspective there are three features of the organization that influence his engagement in collaboration. Firstly, organizations have different absorptive capacity. The higher the capacity of an organization to identify, assimilate and exploit new external knowledge (Cohen and Levinthal, 1990), the higher his incentives to collaborate. Secondly organizations may have different models of knowledge valuation or management (Dasgupta and David, 1994; OwenSmith and Powell, 2004). The more an organization prioritizes accessibility over appropriation, the more open to collaboration it will be. This choice depends on the institutional nature and the strategic positioning of the organization. Finally, organizations differ on their size. Since relations construction and maintenance is expensive in time and 
resources, we can expect that larger organizations, with more resources, will be more active in collaboration than small ones.

Network hierarchy refers to the heterogeneous relational capabilities of organizations in the cluster, reflecting an unequal distribution of power in the cluster. Organizations with many relations, the core, may co-exist with others loosely connected, the periphery. The first, on the top of the hierarchy, have a prominent position to lead the systemic technological process. The second, in the lower levels of the hierarchy, bring the different complementary modules to integrate.

We can consider clusters as successful when they manage to impose standards or dominant designs in a given moment of time. Consequently, when products are complex, the need to construct linking mechanisms among the different components increases (Tushman and Murmann, 1997). Hierarchical networks become efficient structures to set up compatibility and interoperability among the different components in order to reduce system dysfunctions and enhance diffusion. So, clusters are the locus for imposing integrated technological systems, and hierarchical structures a necessary condition.

\section{H1: Network hierarchy displays a positive effect on cluster innovative performance}

\subsection{Assortativity}

Innovation is the result of a re-combination process, where blocks of existing knowledge are melded for new knowledge creation. So, although hierarchy matters to organize the collective process, innovative performance will also depend on the structural degree of openness. It is not only a matter of having some leading core firms or institutions to organize the process, but also about how these different hierarchical levels are interconnected. We refer to it as the assortativity property of networks. It reflects the tendency of nodes in a network to connect with other nodes that have similar or dissimilar degree. A network is assortative when highly connected nodes tend to interact with highly connected nodes, and poorly connected nodes with poorly connected nodes. At the opposite, a network is disassortative when highly connected nodes tend to interact with poorly connected nodes, and conversely.

Network structural properties emerge with the network evolution manifested by nodes entry (or exit) and by their decisions in the formation or disruption of relations. Partners selection decision considers, among other factors, the existing network structure as well as the particular structural position of certain nodes that make them more or less attractive (Ahuja $e t$ al., 2009; Baum et al., 2012) ${ }^{1}$. When closure behavior dominates bridging behavior in partners' selection, assortative networks emerge. Organizations create new relations with organizations already collaborating with their own partners. Their motivations for such behaviors are enhanced trust, lower monitoring costs, and lower risk of opportunistic behaviors. Contrary, when bridging behavior dominates closure behavior disassortative networks emerge. Organizations adopt a disruptive relational strategy and build up new partnerships with isolated organizations or disconnected groups of organizations. In doing so they look for new and no redundant knowledge that enhances higher innovative potential.

Assortative networks are closed. There are groups of organizations that collaborate, but these

\footnotetext{
${ }^{1}$ In the establishment of new relations and the selection of partners individual and dyadic features also matter. The firsts, explained above, refers mostly to size, absorptive capacities and knowledge management strategy. The second refers to the similarities or differences between both potential partners. The proximity approach gives a powerful framework to integrate five different dimensions (Boschma, 2005).
} 
groups are not properly connected. Consequently, there is a redundancy of knowledge flows within the network that may produce negative lock-in and reduce the cluster innovative performance. Due to an excess of conformism in the relational pattern, the new explorative ideas that are often produced in the periphery by new SMEs do not reach the exploitation phase in the core of the cluster. The core and the periphery of the network are not sufficiently connected, i.e. there are important missing links between the leading organizations in the core and the burgeoning periphery. Contrary, with disassortative networks, the organizations in the top of the hierarchy multiply their relations with the periphery. Leading organizations have access to many more sources of new knowledge. Consequently, innovation and the exploitation of this innovation are enhanced. With disassortative networks, the lock-in in a technological trajectory does not imply a cluster lock-in.

\section{H2: Network assortativity has a negative impact on cluster innovative performance.}

\subsection{Hierarchy and assortativity along industrial cycles}

Industries suffer deep transformations as time goes by. Along the industry life cycle, demographic and innovation patterns as well as market competition regime change (Anderson and Tushman, 1990; Utterback and Suárez, 1993; Klepper, 1997). In early stages, industrial output and new firms entries grow at high rates. At the same time, the number of exits is low, so the number of firms in the industry grows. From the technology perspective, the industry is still in the ferment era, a dominant design or standard has not emerged yet. Therefore, firms offer many different versions of the product and the competition regime is driven by innovation. There is a competition "for the market" and not a competition "in the market". With time, although market keeps growing entry of new firms slows down and existing firms start to exit. Consequently, the industrial organization changes. It ossifies around a reduced number of firms, and the emergence of a dominant design or standard. The nature of competition shifts towards price considerations and the aggregation of complementary services and utilities. As a result, process innovations efforts to cut costs gain importance to the detriment of product innovations.

To the extent that industrial organization and the competitive regime change along the industrial life cycle, we can expect a modification of the influence of hierarchy and assortativity on cluster performance across industrial stages. ter Wal and Boschma (2011) discuss the relation between network configurations evolution and the industry life cycle. They argue that, at the emergence stage, networks are quite unstable and not hierarchical given the sharp uncertainty about technological developments. In the growth stage, the network evolves toward a stable core-periphery structure due to the prominence of preferential attachment mechanism (Orsenigo et al., 1998), a hierarchical structure emerges. When the industry reaches maturity networks in the industry get locked-in due to the fixed patterns of interaction and the higher probability of peripheral nodes to exit. This trajectory may have two possible issues. On the one hand, the introduction of a new radical technology may start a new industrial and network cycle. The new cycle can be structure-reinforcing or structure-loosening depending on the fact that the organization introducing the breakthrough was in the core or in the periphery (Madhavan et al., 1998). On the other hand, if no radical new technologies are introduced, the industry decline, firms exit continues and the network disappears. The evolution towards one or the other trajectory depends on the assortative or disassortative nature of the network.

H3: Hierarchy and assortativity have different influence of cluster innovative performance when the industry is in a growing stage or in a maturity stage. 


\section{Data and methods}

\subsection{Research setting}

We situate our study in the context of European mobile phone technological domain. During the last 30 years mobile phones have completely changed from pure voice-communication devices to multi-functional handsets. Nowadays, smartphones integrate voice-communication with digital camera, music player, payment systems, GPS, gaming or numerous Internet services. This process, based on technological convergence and modularity, has transformed mobile phone into a transversal technology with very flexible frontiers in continuous expansion, i.e. mobile phones are complex systems materializing the new mobility paradigm.

A succession of mobile phone generations has accompanied such product transformation. From the $1 \mathrm{G}$ to the current $3 \mathrm{G}$, or incipient $4 \mathrm{G}$, mobile phone communications have increased their capacity, both in higher transmission speed and in richer content of the message. Each generation is based on a different communication standard. The analogue $1 \mathrm{G}$ was superseded by the digital 2G. The GSM standard, impulzed by the European Commission, overcame the limits of the analogue systems in terms of efficiency in the radio-spectrum allocation and in terms of interoperability. GSM was a success. From the mid-90s mobile phone markets experienced tremendous growth, and they achieved penetration rates around $100 \%$ in most European countries in early-2000s. At this stage competitive pressure increases and traditional strategies of product customization and cost reduction become important. They go with new product developments consisting in the aggregation of functionalities and services, i.e. new product innovations. This growth and the proliferation of new services encouraged the development of a new standard, the 3G (UMTS).

In the late 90s, a combination of low interest rates and high growth rates in ICT related sectors generated optimistic expectations on company future profits. They rooted a stock market bubble anticipating further rises. This euphoria leads mobile phone operators in Europe to spent large amounts in $3 \mathrm{G}$ licenses auctions and mergers. However, they underestimated the cost of network development, the difficulty and cost of developing futuristic product and services design and the difficulties to develop new business models for voice and data in 3G, compared to mainly voice in 2G (Dunnewijk and Hultén, 2007). Contrary, they overestimated the users' demand of 3G services (Ansari and Garud, 2009). The financial bubble crash of March 2000 reveals these difficulties and was source of numerous companies' bankruptcies and massive restructuration in the mobile phone sector. This reorganization made emerge two different strategies for the transition from $2 \mathrm{G}$ to $3 \mathrm{G}$ : migration by big leap forward, or migration by small steps though EDGE or GPRS standards, also called $2.5 \mathrm{G}$.

Nowadays, the main players of the mobile phone technological domain continue to be network operators and manufacturers or Original Equipment Manufacturers (OEMs). The core business of network operators is to attract paying consumers to the use of services on their telecom networks that convey voice and data (e.g. Vodafone, Telefónica, T-Mobile ...). OEMs refer to organizations that manufacture and brand handsets (e.g. Nokia, Eriksson ...). However, the competitive pressure, the integration of new functions and the rapid product change has pushed the OEMs to interact and outsource to third parties certain number of activities: suppliers of components, assemblers of electronic components, prototype developers, universities... This has contributed to open the mobile phone sphere to actors originally from different domains, either as providers of new piece of knowledge to integrate 
in the system (e.g. Microsoft) or to become an OEM (e.g. Apple, Google).

The mobile phone technological domain in Europe is an interesting context for the study of the influence of network hierarchy and network assortativity for two main reasons. Firstly, it is a sector characterized by the integration of complementary modules constituting complex system, rapidly shrinking product life cycles, and strong standardization processes. So, organizations are pushed to interact with others in order to get new knowledge and competences in sufficiently short time to remain competitive, i.e. knowledge networks are central for the technological domain evolution, and clusters are well known locus to enhance such knowledge flows. Secondly, European organizations and public authorities have been crucial for the mobile phone development. On the one hand, they established the GSM standard that enhances the diffusion of mobile phones. On the other hand, four out of five players that dominated the GSM market were European (Nokia, Ericsson, Siemens and Alcatel). This indicates the importance of European regions in this technological domain. Thus, we can expect to find several regions with a relatively important concentration of interacting organizations on mobile phone related activities.

\subsection{Data}

\section{Data sources and extraction}

To test our hypotheses we exploit data of different nature from two different sources. Data on organizational networks are constructed through $R \& D$ project collaborations based on European public funded projects by Framework Programs (FP1-FP7) from the Syres EUPRO database. FP are created by the European Union (EU) to support and encourage research. Although the strategic objectives and thematic priorities may vary between funding periods, they follow a simple schema in which potential participants meet other organizations (firms or institutions) to elaborate and submit a proposal to the Commission. Funded projects may be quite heterogeneous in their field, duration and number of partners, but to the extent they try to foster trans-national cooperation they always involve organizations from several EU countries.

Syres EUPRO contains information on all projects funded on FP1-FP7 as well as the organizations involved on them from 1984 to 2010. Syres EUPRO is based on raw CORDIS data, but it has been improved at several points: $i$ ) identification of unique organization name, ii) identification of unique organization type iii) creation of economic meaningful sub-entities iv) identification of genealogy of participants, and $v$ ) regionalization (NUTS1 and NUTS2 level) (Barber et al., 2008). For each project, it lists the title and a brief description, start and end dates, broad subject categories and the organizations involved. For each organization participating in a project, it lists the name of the organization with unique identifier at subentity level, organizational type, non-standardized address and standardized location at NUTS1 and NUTS2 level.

As for previous contributions (Autant-Bernard et al., 2007; Scherngell and Barber, 2011; Balland et al., 2013c), several reasons legitimize the choice of public funded R\&D collaborations. Firstly, steps towards standards construction with greater signal capacity and security, and the integration of new services result of collective projects. Secondly, based on strategic consideration European governments tried to boost the mobile phone industry from the very beginning, with particular concerns in intra-European compatibility and roaming. EU funds to finance these projects were fundamental. The consequence was the development of the GSM common standards, and the early growth of the European mobile phone sector. 
Finally, many governments have had a prominent role in the sector through the actions of the monopolistic position of former national operators and the national regulatory agencies.

To measure cluster innovative performance, we use patent applications counts to the European Patent Office (EPO) regionalized by the inventors address. Although patents are just a partial measure of the innovative performance of regions, they have been largely used to this end (Fleming et al., 2007; Lobo and Strumsky, 2008; Breschi and Lenzi, 2012), because they contain abundant information, they are of relative easy access, and they are quite homogeneous across regions. We select patents related to the mobile phone technological domain using PATSTAT database elaborated by the EPO. We regionalize these patents by inventors address using REGPAT database elaborated by the OECD and based on PATSTAT database $^{2}$.

Mobile phone has become a transversal technology. To include the different mobile phone dimensions we have used a keywords approach. We select mobile phone projects and patents from Syres EUPRO and PATSTAT databases by looking for certain key-words in their abstracts. We define "mobile", "phone" and "telecommunication" as basic recursive keywords, and we use boolean operators to combine them with specific words associated to four layers that define the mobile phone industry: $i$ ) infrastructure layer, $i$ i) security layer, $i i i$ ) service/software layer, $i v$ ) terminal layer. The selection of these keywords is based on expert advice.

Our final data on projects and patents span from 1988 to 2008. The keyword methodology produced a sample of 978 projects and 4124 participants from the collaborative R\&D base. Projects are assigned to a year on the base of their starting date. For the patents database we get a sample of 8692 patent applications ${ }^{3}$.

\section{Network definition}

We construct networks for each year of the period 1988-2008. Collaborative R\&D networks are built from affiliation matrix based on projects. Affiliation matrix contains organizationby-project information: $a_{i j}=1$ if the $i$ th organization is involved in the $j$ th project and 0 otherwise. From the affiliation matrix we get an organization-by-organization unimodal matrix: if $b_{i j} \geq 1 i$ th and $j$ th organizations have at least one project in common, if $b_{i j}=0$ they do not collaborate.

Projects are annually assigned by their starting date. Since the average duration of projects is 30.6 months, we used 3-years moving windows to construct collaborative R\&D networks. Due to the objectives of European cooperation, FP projects are conditioned to the involvement of partners from different countries. We deal with this bias by assuming that when two organizations of the same region are in a common project they know each other, and so they have an effective collaboration. Contrary, for organizations of two different regions we assume that collaboration exists only when they are in at least two common projects in the same year-window, otherwise there is only a policy bias and the effective collaboration does not exist (Autant-Bernard et al., 2007). Consequently, two organizations in the same region have a relation at year $\mathrm{t}$, if they collaborate in at least one project in year $t, t-$ 1 or $t-2$. Two organizations in different regions have a relation at year $t$, if they collaborate in at least two projects in year $t, t-1$ or $t-2$.

\footnotetext{
${ }^{2}$ April 2012 version

${ }^{3}$ Patents applications are selected considering DOCDB patent families to avoid double counts.
} 


\section{Geographical scale}

The geographical boundaries of clusters are very elastic, and systematic data at cluster level are rare. So, although we acknowledge that clusters geographical borders usually do not match with administrative divisions, we are constrained by data availability. Then, organizational networks and patent counts are regionalized at NUTS2 level. This is the smallest aggregation level to locate organizations in Syres EUPRO database.

The calculation of network properties requires networks with a minimum size. Networks with too small number of nodes do not have a minimal critical mass to properly calculate structural properties. To avoid this problem we decide to work only with the 19 NUTS2 regions that have more than 50 participations along the whole period (1988-2008). So, we obtain a panel with 19 regions and 21 years.

\subsection{Dependent variable}

We measure regional innovative performance of clusters by the number of regional patent applications per year. Patent applications are annually assigned based on their "priority date", which is considered as the closest date to the invention act. Regional assignation is done by inventors address. In case of patents applications with several inventors in different locations a complete assignment is done, i.e. patent application $X$ is assigned to region $r$ when an inventor of the patent $X$ is located in region $r$. As a result we have a discrete variable taking 0 and positive integer values.

\subsection{Independent variables}

\section{Measuring network hierarchy}

Crespo et al. (2013) measure the level of network hierarchy as the slope of the degree distribution, i.e. the relation between nodes degree and their rank position. We sort nodes by degrees from the largest to the smallest, and transform them in log-log scale ${ }^{4}$.

$k_{h}=C\left(k_{h}^{*}\right) a$

$$
\log \left(k_{h}\right)=\log (C)+a \log \left(k_{h}^{*}\right)
$$

Where $k_{h}$ denotes the degree $k$ of node $h, k_{h}{ }^{*}$ denotes the rank of node $\mathrm{h}$ in the distribution, $C$ is a constant and $a$ is the slope of relation. By construction, $a$ will take 0 or negative values. In order to simplify interpretation, we transform it in absolute terms. If $a$ has a high value, in absolute terms, the network will display a high level of hierarchy. There will be some nodes with many relations in a prominent network position and others with few relations. Contrary, low $a$ values, in absolute terms, correspond to a network structure with flat hierarchy. Consequently, all nodes have more or less the same number of relations, relational capabilities are quite homogeneous and there is no leading organization.

In hypothesis 1, we argue that hierarchy has a positive impact on cluster innovative performance. However, this effect might reach a threshold beyond which higher hierarchy damages innovative performance. To test for non-linear effects we introduce the squared term

\footnotetext{
${ }^{4}$ To avoid non existing logs for isolate actors we consider that all actors have at least one relation with themselves
} 
of the network hierarchy measure.

\section{Measuring network assortativity}

To measure the level of assortativity or disassortativity of networks we use degree correlation as defined by Crespo et al. (2013): it is the slope of the relation between nodes' degree and the mean degree of their local neighborhood. For each node $h$ we calculate the mean degree of his neighborhood $V_{h}$. A node $i$ is in the neighborhood of node $h$ when both of them are in the same region, and they have, at least, one collaborative project together, i.e. they have a relation. If $k_{j}$ is the degree of node $k$ the mean degree of node $h$ can be calculated as follows:

$\overline{k_{h}}=\frac{1}{k_{h}} \sum_{i=v_{h}} k_{i}$

Then we estimate the relationship between nodes' degree and the mean degree of their neighborhood:

$k_{h}=D+b k_{h}$

Where $D$ is a constant and $b$ is the degree correlation. By construction $b$ is enclosed between one and minus one. If $b$ is positive and get closer to one, then the network is highly assortative, meaning that highly connected nodes tend to interact with highly connected nodes, and poorly connected nodes with poorly connected nodes. At the opposite, if $b$ is negative and get closer to minus one, the network is disassortative, meaning that highly connected nodes tend to interact with poorly connected nodes, and conversely.

\section{Interactive variables}

We check for interplay between assortativity and hierarchy with interactive variables. To do so, we create dummy variables to split observations in two categories: $i$ ) observations with high hierarchy, in this case the variable takes the value 1 if degree distribution is above the median, 0 otherwise; and ii) observations with low hierarchy, in this case the variable takes the value 1 if hierarchy is below the median, 0 otherwise. We create interactive variable by multiplying these two dummies with degree correlation. With this method we test if degree correlation has a different impact when associated to networks with high or low hierarchy levels. To test hypothesis 3 we use interactive variables too. We create two dummy variables to split observations in two sub-periods, prior and after $2000^{5}$. We multiply them by degree correlation and degree distribution to identify differential effects of hierarchy and assortativity in the first and second period, i.e. prior and after the bubble crash.

\subsection{Controls}

To rule out potential bias and possible competing hypothesis we introduce control variables at network and regional level. Small world networks may enhance regional innovation by their combination of local dense interaction and short average path length. While the first enables trust formation and collaboration, the second favors connectivity and the arrival of new knowledge. We introduce clustering coefficient (CC) computed as "the average fraction of pairs of neighbors of a node which are also neighbors of each other" (Newman, 2000) to control for the local cliquishness effect.

\footnotetext{
${ }^{5}$ The dummy for the first period takes the value 1 for years 1988-2000, and 0 otherwise. The variable for the second period takes the value 1 for year 2001-2008, and 0 otherwise.
} 
To control for the short path length and the existence of non-redundant relations, we elaborate two measures based on their different geographical scope. Internal reach (IR) focuses on within-region relations. It is calculated as the average of the weighted distances of each local node $j$ with all other local nodes $k$. It takes the value 0 if all local nodes are isolates, and it takes the value 1 when every local node is connected with a path of distance one to all other local nodes (Breschi and Lenzi, 2012):

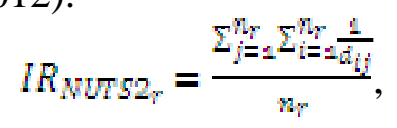

where $n_{r}$ denotes the number of inventors located in region $r$, and $d_{i j}$ the geodesic distance between organizations $j$ and $i$, belonging to the local network of region $r$.

Contrary, external reach (ER) focuses on between-region relations, i.e. the relational distance between local nodes and non-local nodes: the pipelines. We compute it as the average of the weighted distance of each local node $j$ with all other non-local nodes $h$. Similarly, it takes the value 0 if non local actor has an external tie, i.e. a relation with an actor in another region. It takes the value of 1 if all actors in a region are connected by a path of length one to all actors in all other regions (Breschi and Lenzi, 2012):

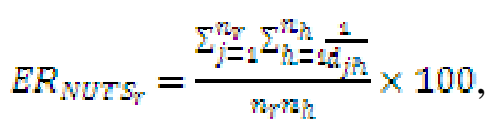

where $n_{r}$ denotes the number of inventors located in region $r$, and $n_{h}$ the number of inventors located in all other regions. Similarly, $d_{j h}$ denotes the distance between inventors $j$ and $h . \square$

We include two more controls about the cohesion of the local inter-organization network. Network size and network density account for the number of nodes and the number of ties. Network size is simply the number of organizations in the region (Ln number of org $^{6}$ ). Network density is calculated as the actual over the potential number of ties among local organizations. It takes the value 0 when all local nodes are isolates, and it takes the value 1 when all local nodes form a clique.

In addition to network features we control also for regional features that may influence their patenting capacity. We include variables for the regional availability of resources and size. Firstly, R\&D expenditures are a fundamental indicator for the regional resources mobilized for innovative activities. However, systematic data at NUTS2 level were not available for the period of analysis. However, given the fact that location patterns of R\&D collaborations tend to be stable over time (Acs et al., 2002), the use of fixed effects models should account for much of the variation (Fleming et al., 2007; Lobo and Strumsky, 2008). We support it with three key variables added to our model. Firstly, we use the number of inventors in region $i$ at year $t$ (Ln inventors). It accounts for the number of people actively engaged in inventive activities. Furthermore, we use regional population in thousands of inhabitants at year $t$ to control for regional size (Ln population). Finally, to control for urbanization economies, we use population density calculated as population over regional land extension in square kilometres (Ln population density).

Our model considers regional knowledge bases too, a fundamental regional feature that may affect patenting activity of regions in the mobile phone sector. To this end, we compute controls for knowledge diversity and for knowledge specialization. Firstly, we computed

\footnotetext{
${ }^{6}$ All independent count variables are introduced in logarithmic terms. 0 count cases have been changed by 0.01 in order to avoid non-existence of $\ln (0), \ln (0.01)=-4.61$.
} 
Herfindahl-Hirschman Index using the shares on technological domains in each region $(H H I$ technology). The EPO examiners assign patents to technological fields following the International Patents Classification (IPC). We use patent classes from patents assigned to region $i$ at year $t$ to calculate $H H I$ technology variable. It varies between 0 and 1 , and measures the extent to which a region is specialized in a narrow set of technologies (high HHI technology), or it has a diversified knowledge bases (low HHI technology). Secondly, we computed a mobile phone specialization index based on the number of inventors. For each region $i$ at year $t$ we calculate the number of regional inventors in the mobile phone sector over the total number of inventors in the region. We compare it with the same ratio aggregated for all regions. If the resulting index is superior (inferior) to 1 the region is (not) specialized in mobile phone technological domain. While HHI technology variable may indicate diversification or specialization in any technological field, specialization index variable focus only on mobile phone sector.

\subsection{Estimation framework}

To measure the innovative capacity of regions we construct the variable regional patent applications on mobile phone technological domain annualized by priority date. We model it for a period of 21 years going from 1988 to 2008, and for 19 NUTS2 European regions. Regional patent applications can only take integer non-negative values. Consequently, the appropriate estimation methods are count models based on Poisson distribution:

$\operatorname{Pr}(Y=y)=\frac{e^{-\mu} \mu^{y}}{y !}$

Where $\mu$ is the rate parameter. In the Poisson distribution the mean and the variance are equal (equidispersion). To obtain the Poisson regression model we specify $\mu_{i}$ with the independent variables $X_{i}$ under the standard assumption of exponential mean parametrization: $\mu_{i}=e^{x_{i}^{2} \beta}, i$ $=1, \ldots, N$. However, the Poisson regression rarely fits in practice because, as in our data, the variance is greater than the mean: data are overdispersed. Under overdispersion the Poisson estimates are consistent but inefficient, and underestimate standard errors leading to spuriously highly $z$-values. Negative binomial models let solve this accounting by unobserved cross-sectional heterogeneity with a mixture of Poisson and Gamma distribution:

$$
\operatorname{Pr}\left(Y_{i}=y_{i}\right)=\frac{\Gamma\left(\alpha^{-2}+y_{i}\right)}{\Gamma\left(y_{i}+1\right) r\left(\alpha^{-1}\right)} r_{i}^{\gamma_{i}}\left(1-r_{i}\right)^{-4} \text {, where } r_{i}=\frac{\mu_{i}}{\mu_{i}+\alpha^{-1}}
$$

Negative binomial model is preferred because our data exhibit overdispersion, we reject Poisson model at $p<0.000$.

Given the panel structure of our data we modeled regional mobile phone patens with conditional fixed-effects specification to control for unobserved heterogeneity across regions ${ }^{7}$, i.e. it considers within-region variation only. Generational effects are directly estimated by including dummy variables for each generation existing in the mobile phone history. Consequently, the basic negative binomial model we estimate has the following form:

$\ln \left(\gamma_{i t}\right)=\sum_{j=1}^{I} \beta_{j} X_{i t j}+\sum_{h=1}^{H} \gamma_{h} Z_{i t h}+\alpha_{i}+\phi_{g}+\varepsilon_{i t}$

\footnotetext{
${ }^{7}$ Either fixed-effects or random-effects provide consistent results, but the Haussman test supports the use of fixed effects.
} 
Where the dependent variable is the number of patent applications on the mobile phone sector of region $i$ at year $t$. The independent variables $X$ is a vector with the network structure variables that test our hypothesis (degree distribution and degree correlation), $Z$ is a vector with the network and regional controls we use, $\alpha$ is the regional fixed effect, $\varphi$ refers to the mobile phone generation fixed effect and $\varepsilon$ is the idiosyncratic error term ${ }^{8}$.

\section{Results}

Tables 1 and 2 present the descriptive statistics and the correlation values for all variables. The correlation values are relatively low for most of the variables. Higher values concern variables catching network structural properties. This is often the case given the influence of network size over all network measures. However, we compute the variance inflation factors and we find that multicollinearity is not a problem.

Table 1: Descriptive statistics

\begin{tabular}{|c|c|c|c|c|c|}
\hline Variable & Mean & Std. Dev. & Min. & Max. & $\overline{\mathrm{N}}$ \\
\hline Patent applications & 8.76 & 15.94 & 0 & 112 & 399 \\
\hline External reach & 3.48 & 3.66 & 0 & 25.17 & 399 \\
\hline Internal reach & 0.98 & 1.31 & 0 & 9.08 & 399 \\
\hline Clustering coef. & 0.41 & 0.39 & 0 & 1 & 399 \\
\hline Density & 0.13 & 0.18 & 0 & 1 & 399 \\
\hline Ln number of org. & 2.32 & 1.33 & -4.61 & 4.72 & 399 \\
\hline Ln inventors & 6.46 & 1.2 & 2.2 & 8.84 & 399 \\
\hline Ln population & 15.09 & 0.57 & 13.77 & 16.27 & 399 \\
\hline Ln population density & 6.24 & 1.42 & 4 & 9.13 & 399 \\
\hline HHI technology & 0.01 & 0.01 & 0 & 0.12 & 399 \\
\hline Specialization Index & 1.84 & 3.46 & 0 & 38.5 & 399 \\
\hline Degree distribution (abs) & 0.5 & 0.27 & 0 & 1.05 & 399 \\
\hline Degree distribution $^{2}$ & 0.07 & 0.08 & 0 & 0.37 & 399 \\
\hline Degree Correlation & 0.72 & 0.27 & -0.59 & 1 & 399 \\
\hline
\end{tabular}

\footnotetext{
${ }^{8}$ We run all the analysis with STATA 11
} 
Table 2: Variables correlation

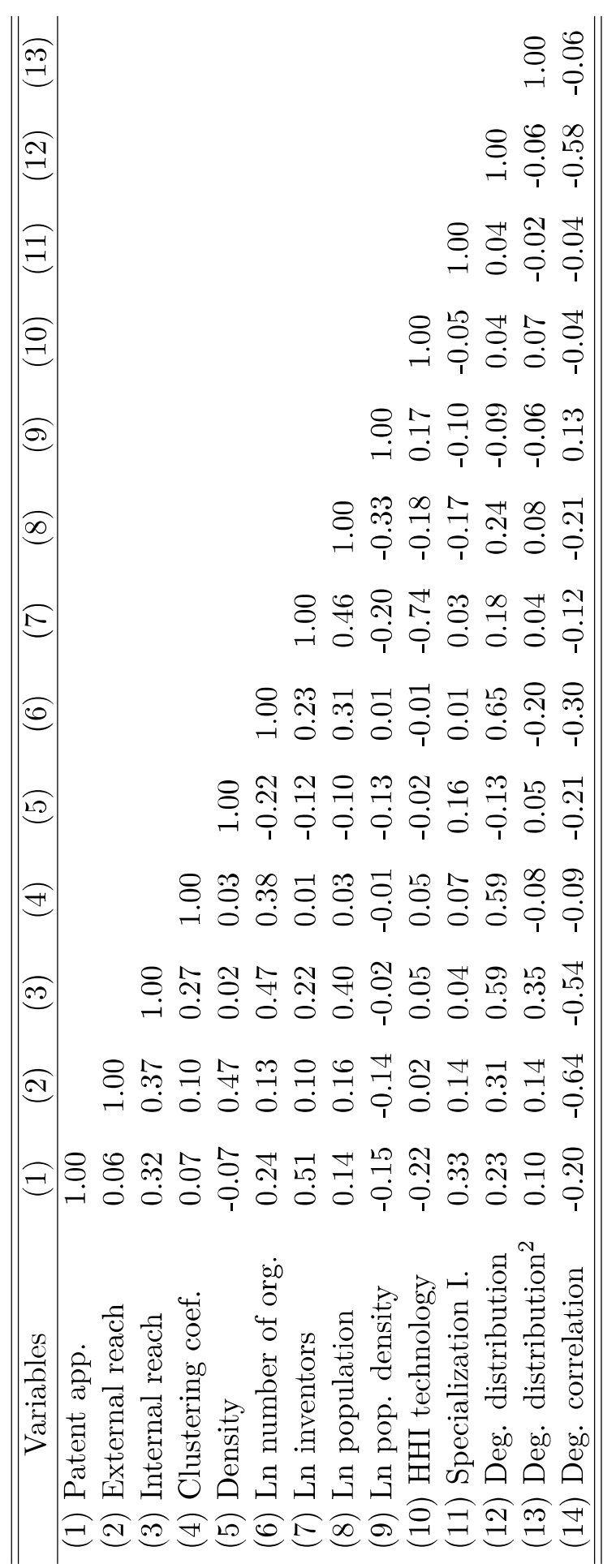

Table 3 present the modeling results to test our hypothesis. Model 1 is the baseline model with all controls. Model 2 includes the explanatory variables for hierarchy and assortativity, and model 3 examines their interaction. Finally, model 4 checks for differential impact of the explanatory variables in the emergence and maturity stages of the mobile phone sector. Model 4 has the best fitting.

In model 1 the coefficient estimate of Ln inventors is positive and significant since it captures the resources potentially available on the region for innovative activity. The unexpected 
negative and significant sign of Ln population probably indicates an overlapping effect with the Ln inventors variable. The variables $L n$ population density is positive and significant. Thus, it shows that positive urbanization externalities dominate congestion effects for mobile phone patents production. The positive and significant effect of specialization index as opposed to the non-significant effect of HHI technology underline the role of specialization economies over the Jacobian externalities for the regional production of mobile phone patents. For network controls, we have that external reach has an unexpected negative and significant effect. It may indicate the risk of too much outward-looking relations (Bathelt et al., 2004), in particular with small networks. This "excess" of external relations is linked to the nature of the data, since FP-projects are conditioned to non-local cooperations. Internal reach and clustering coefficient are both negative and non-significant reflecting the ambiguous results of the empirical small world literature. While Breschi and Lenzi (2012) find support for the small world model, results of Fleming et al. (2007) are much less concluding due to insignificancy of variables, particularly for clustering. Finally, density is positive and significant, and network size is positive and non-significant.

Our first hypothesis finds support in model 2. Once accounting for regional characteristics and basic network connectivity, the linear and nonlinear effects of degree distribution are both positive, although only the nonlinear is significant. So, strong hierarchy in local networks of organizations in a given technological domain favors patenting activity. The marginal effect shows that an increase of 0.1 in degree distribution implies an increase of $0.97 \%$ in regional mobile phone patent applications 9 . Model 2 also supports our second hypothesis about the effects of assortative networks on innovative performance. We find that the degree correlation coefficient is consistently negative and significant for regional patenting activity: an increase of degree correlation 0.1 units produces a reduction of $0.076 \%$ in the regional patent counts on the mobile phone technological domain, i.e. more assortative networks are less performing.

Model 3 studies potential interaction between both properties. We construct two interactive variables that split degree correlation in two groups: degree correlation associated with high degree distribution, and degree correlation associated with low degree distribution ${ }^{10}$. In model 3 the conclusions for hierarchy hold. Similarly, the coefficients of both degree correlation variables are still negative and significant. So, assortative networks have a negative impact on regional patents production either when the network has a strong or a weak hierarchy. However, a Wald test indicates that both coefficients are significantly different; assortativity has a bigger negative effect on innovative performance when the network has low hierarchy ${ }^{11}$.

In model 4 we test our hypothesis 3 on the differential effect of hierarchy and assortativity along the technological domain cycle. We extend model 2 to test if degree distribution and degree correlation change their influence on innovative performance prior and after 2000 . We test this hypothesis with interactive variables obtained as a product of our explanatory variables (degree distribution and degree correlation) and two temporal dummies, one for the pre-crash period (1988-2000) and other for the post-crash period (2001-2008). We find partial support for hypothesis 3. For degree distribution, the linear effect is significant in both periods, but it has a negative impact on the patenting performance of regions in the first period, and a positive effect in the second. The Wald test confirms that both coefficients are significantly different. Concerning degree correlation, the estimated coefficients are negative and significant for both periods, i.e. assortativity damages innovative performance of regions in mobile phone technological domain prior and after the telecom crash. Thus, model 4

\footnotetext{
${ }^{9}$ Marginal effect computed at the mean value of all variables in the model.

${ }^{10}$ A network is qualified as highly (lowly) hierarchical when its degree distribution is over (below) the median.

${ }^{11}$ We have also checked as percentile 66 as cut point for high/low hierarchy. Both degree correlation variables have a negative effect on regional production of patents, but it is only significant when associated with low hierarchy suggesting a compensation effect between both, i.e. networks with strong hierarchy cancels the negative effect of assortativity.
} 
validates hypothesis 3 for hierarchy, but not for assortativity.

To sum up, these results support the first two hypothesis on hierarchy and assortativity: (1) strong hierarchy and (2) disassortativity increase patenting activity of region in the mobile phone technological domain. However, the hypothesis 3 on the shifting role of these properties along the technological cycle finds weak empirical support, it holds for hierarchy but not for assortativity.

Table 3: Conditional fixed effects negative binomial of patent applications (1988-2008)

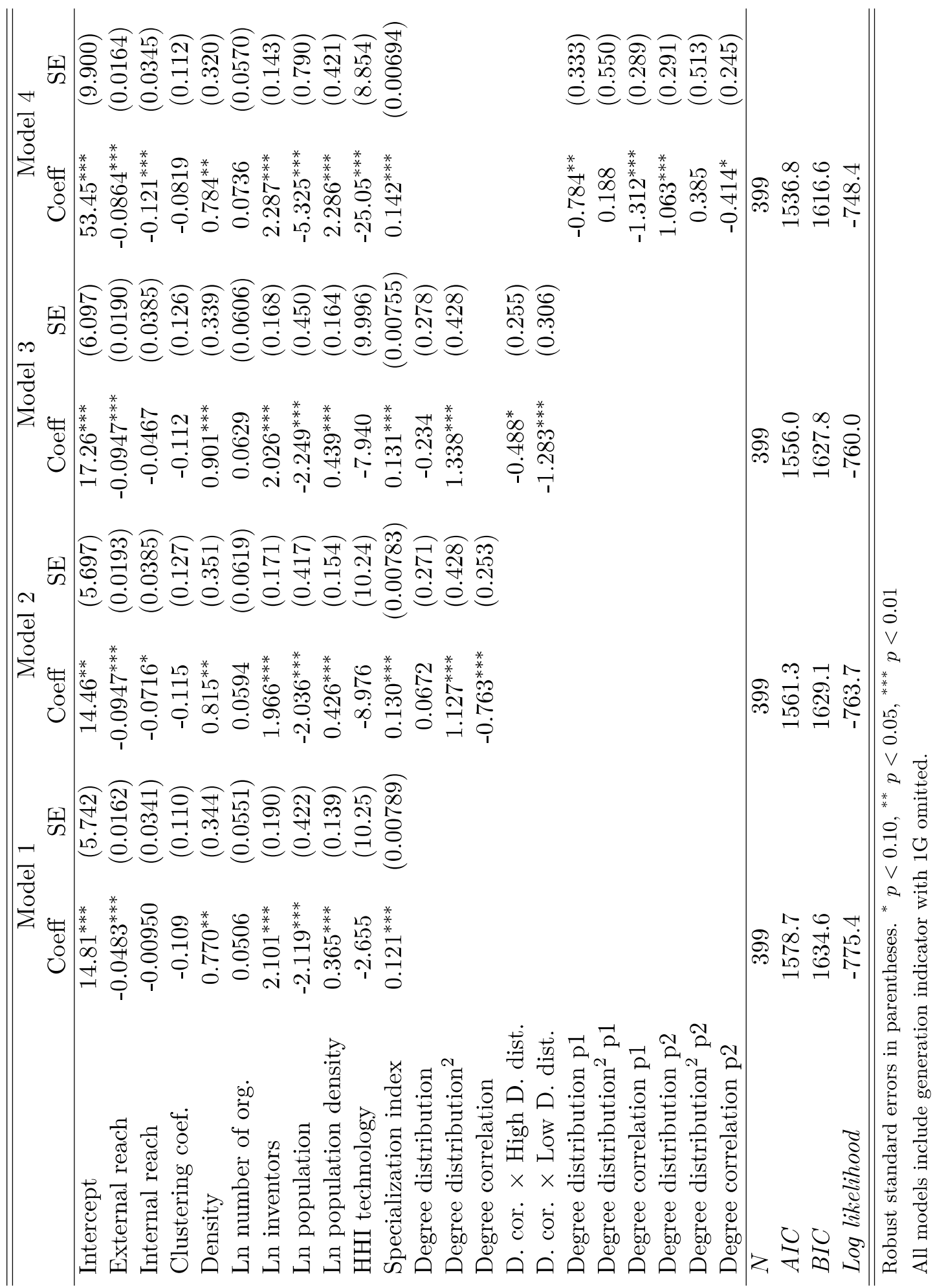


We tested the robustness of the results to alternative model specifications. We have assumed that innovative performance of regions is continuous. We have also done the analysis by considering the annual relative performance of regions as dependent variable. We sort the regions by their number of patents in year $\mathrm{t}$, and we construct a categorical ranking variable by assigning 2 for the top 3 regions, 1 for regions in positions 4 to 6 and 0 otherwise. Since the order of categories was meaningful we estimated an ordered probit model. The results of the analysis were consistent with those presented in table 3 and discussed above.

From 1988 to 2008 there are several regions that do not get any mobile phone patent in certain years. So, to deal with an eventual "excessive" number of regions with 0 counts, we estimated zero-inflated negative binomial models $(\mathrm{ZINB})^{12}$. ZINB models rely on the assumption that zero-counts and positive-counts comes from different data generating processes. Thus, ZINB are two-parts models, consisting of both binary and count model section. In the binary section we estimated a probit model with variables referring to the regional features. In the count section we include regional variables and network variables. The results concerning degree distribution and degree correlation are consistent with the regressions presented in table 3 too. In particular the inclusion of degree distribution and degree correlation variables improved significantly the overall fit of the model as compared with the baseline model ${ }^{13}$.

\section{Discussion}

These findings provide interesting evidence for a better understanding of the critical role of network properties for clusters performance, and then, complement a growing literature on that purpose (Owen-Smith and Powell, 2004; Boschma and ter Wal, 2007; Broekel and Graf, 2012; Balland et al., 2013c). Moreover, these findings corroborate evidence on particular industrial dynamics in which knowledge variety and complementarities, technological integration and standardization influence the structural organization of clusters, their long run dynamics in a context of competing regions, as well as their endogenous capabilities of resilience (Crespo et al. 2013; Martin et al. 2013)

First of all, model 2 supports the hypothesis according to which, along the whole period of time, stronger network hierarchy favors innovative performance of clusters, while stronger network assortativity damages it. On a one hand, European clusters that have better performed are the ones which contributed to bringing out few but dominant and leading companies, able to coordinate a wide range of other organizations holding separated but complementary pieces of knowledge, and able to integrate them in a systemic and complex technology. On the other hand, beside the critical role of hierarchy, the less clusters are assortative, the more their output in terms of patents increases, meaning that competing clusters are the ones that display a wider range of pathways between core-organizations and loosely-connected ones, such as new entrants or spin-offs. To put it differently, the innovative capabilities of clusters do not solely depend on the co-existence of leading organizations with a high relational capacity and other peripheral and loosely-connected ones. The hierarchical structure of clusters had to be coupled with a particular structure of knowledge flows in which new explorative, or even disruptive, ideas find channels to join the experienced and well-established core of leading organizations enabling to turn these ideas into new tradable products for exploitation.

\footnotetext{
${ }^{12} 36 \%$ of our observations have 0 counts.

${ }^{13}$ The estimation of a Hurdle model reached the same conclusions.
} 
These findings tend to confirm a large part of the literature on the complex industrial organization of the mobile phone industry. Concerning the positive role of hierarchy, Funk (2009) and Funk (2011) show that the success of mobile phone OEMs (Original Equipment Manufacturers) in the definition of a dominant design depends on their ability to coordinate a critical mass of complementary products, in order to diffuse the final product as widely as possible. At the opposite, one can expect that flat hierarchy in clusters implies a lack of global vision of the complex device, and then some risks of non-compatibilities or dysfunctions that weaken the ability of the clustered organizations to set up a dominant design. Concerning the negative influence of assortativity, literature has shown that the vertical integration between related and even unrelated features have turned the industry into the production of multifunctional devices (Giachetti and Marchi, 2010). In this context, Koski and Kretchmer (2009, 2010) have found that innovations in terms of openness towards previously unrelated technologies have played a stronger role for the performance of OEMs than the traditional network and epidemic effects at play on the consumer side. Therefore, one might expect that clusters in which leading organizations devote their relational capabilities to connect themselves favor technological standardization. However, it can prevent the entry of potential providers of unrelated assets, redundant knowledge flows and then generate a high risk of conformism.

More outstanding are the findings on network hierarchy and assortativity when we refine the analysis by splitting the period into two sub-periods (Model 4). Indeed, following previous theoretical and empirical attempts (Menzel and Fornahl, 2010; Balland et al., 2013a; Crespo et al., 2013), our period is rather long to be able to capture differentiated effects of these properties on the aggregate performance of clusters along the particular life cycle of the mobile phone industry. In particular, the Internet bubble crash which concerned the whole industry of information technologies constitutes a significant event for the organization of the industry and an important step between its development and its maturity. If the negative role of assortativity remains unchanged when the two periods are taken into consideration, at the opposite, we can see a changing role of hierarchy along the industry life cycle. Here again, our findings corroborate a large part of the literature on industrial dynamics. Indeed, during the first period, the more clusters display a high level of hierarchy, the less they perform in their patenting activities. On the one side, one could interpret that clusters hosting big companies such as national incumbents (traditional network operators) performed less in terms of innovation during the initial stages of development, since their main concern was more to re-orient their customer bases towards the first generation of mobile handsets than to participate to the wave of burgeoning innovations in the mobile phone industry. On the other side, as early demonstrated in the industry life cycle approach of Klepper $(1996,1997)$, small companies and recent entrants are responsible for a large part of product innovations, in an entrepreneurial technological regime which is favorable to innovative entries and unfavorable to well-established big companies. Moreover, the logic of knowledge accessibility in which these burgeoning companies are involved to combine complementary pieces of knowledge is typical of the early phase of cluster formation (Audretsch and Feldman, 1996a), with flat hierarchy, and far from the process of ossification around a couple of leading companies that typifies more mature clusters. The long run analysis of the mobile phone industry by Giachetti and Marchi (2010) confirms our findings. According to them, a large part of innovations during the early and growth phases in the 1980s and 1990s arises more from a structured process of collaboration between OEMs, components suppliers, original design manufacturers and public research organizations, than from the control of the integration process by the oligopolistic networks operators. 
At the opposite, during the second period, strong hierarchy favors cluster performance in patenting activities, together with low assortativity. To explain such a change, the arguments of Klepper $(1996,1997)$ and Audretsch and Feldman (1996a) on the life cycle of the industry and the geographical counterpart still apply, at least partially. As a matter of fact, as in many other industries, and after a growth stage with intensive entries, a shakeout occurs and clusters achieve more or less their final form with a more oligopolistic structure, and the continuation of the spin-off process, that allow clusters to insure their sustainability, rather than to decline (Menzel and Fornahl, 2010; Crespo, 2011). Therefore, the return of the positive effects of hierarchy could be explained by this prototypical trend of industry, where performing clusters are now the ones in which some leading organizations have crossed the chasm between the early and the mass market and are able to coordinate actions and knowledge of other colocated organizations to maintain their position. This explanation might be relevant, but only partially, since Klepper's view of the life cycle of industries, reinforced by the observed patterns of innovation of Abernathy and Utterback (1978), links the ossification of the industrial structure along the cycle of the industry to the changing nature of innovation, which goes from product innovation to process innovation. However, these patterns do not match with the particular long run dynamics of the mobile phone industry. Many authors (Funk, 2009, 2011; Koski and Kretchmer, 2009, 2010; Giachetti and Marchi, 2010) underline the acceleration of the rhythm of product innovations by the well-established companies during the period of shakeout and maturity. These product innovations were driven by the impact of technological convergence between the mobile phone, Internet, computer and media industries, as well as the introduction of other advanced technologies that make handsets "smarter". In this context, competing clusters in the shakeout and maturity phases of the mobile phone industry were the ones which succeeded in mixing the ossified structure with an open network structure that favors connections and knowledge channels between the coreorganizations of the industry and new and fresh unrelated ideas that allow OEMs to increase their portfolio of new applications and uses. Such a pattern shows that the prototypical process of ossification along the cycle of the industry does not go against the persistence of product innovations if network structures exhibit a sufficient level of disassortative relational behaviors. In that sense, model 4 clearly shows that the resilience capabilities of clusters after the telecom bubble crash is linked to the ability of the whole structure of networks to deal with hierarchy and disassortativity, in order to avoid the "trap of rigid specialization" (Grabher, 1993) that generally pushes clusters towards decline.

\section{Concluding remarks}

In this essay, we have tried to contribute to the growing literature on clusters dynamics that puts the structural properties of knowledge networks at the center of the analysis. Our main contribution to this literature shows that for clusters involved in the production of complex and systemic technologies, the properties of hierarchy and assortativity bring new ways to capture the reasons why some clusters perform better than others, and through what kind of structural mechanisms they resist to economic shocks and perform all along the cycle of markets. Previous literature has clearly showed that small-world properties matter for that purpose. Since these properties perfectly capture the trade-off between closure and bridging, or between cohesiveness and openness of networks, they give an interesting view of the mechanisms at play in the structural organization of clusters. Here, we show that considering hierarchy together with assortativity allows going further. They represent properties that put together some traditional basics of industrial organization, such as the process of oligopolization along the cycle of the industry, with the geographical but also relational dimensions of these industrial structures. In particular, our analysis shows that the increasing hierarchy that allows industry to reach maturity does not necessarily lead to lock-in situations 
for clusters that host part of this industry. If the relational structures typifying some of these clusters display a sufficient level of disassortativity to prevent rigidities and preserve openness towards new and fresh knowledge, thus they will maintain opportunities for product innovation in the long run. Other studies, including other industries and other methodologies, will be necessary in the future to confirm these preliminary but promising results.

\section{References}

Abernathy, W. J. and Utterback, J. M. (1978). Patterns of industrial innovation. Technology Review, 80(7):40-47.

Acs, Z. J., Anselin, L., and Varga, A. (2002). Patents and innovation counts as measures of regional production of new knowledge. Research Policy, 31(7):1069 - 1085.

Ahuja, G. (2000). The duality of collaboration: Inducements and opportunities in the formation of interfirm linkages. Strategic Management Journal, 21(3):317-343.

Ahuja, G., Polidoro, F., and Mitchell, W. (2009). Structural homophily or social asymmetry? the formation of alliances by poorly embedded firms. Strategic Management Journal, 30(9):941-958.

Anderson, P. and Tushman, M. L. (1990). Technological discontinuities and dominant designs: a cyclical model of technological change. Administrative Science Quarterly, 35(4):604-633.

Antonelli, C. (2005). Models of knowledge and systems of governance. Journal of Institutional Economics, 1(01):51-73.

Ansari, S., and Garud, R. (2009). Inter-generational transitions in socio-technical systems: the case of mobile communications. Research Policy, 38(2):382-392.

Audretsch, D. B. and Feldman, M. P. (1996a). Innovative clusters and the industry life cycle. Review of Industrial Organization, 11(2):253-273.

Audretsch, D. B. and Feldman, M. P. (1996b). R\&D spillovers and the geography of innovation and production. The American Economic Review, 86(3):630-640.

Autant-Bernard, C., Billand, P., Frachisse, D., and Massard, N. (2007). Social distance versus spatial distance in $\mathrm{R} \& \mathrm{D}$ cooperation: empirical evidence from European collaboration choices in micro and nanotechnologies. Papers in Regional Science, 86(3):495-519.

Balland, P.-A. (2012). Proximity and the evolution of collaboration networks: evidence from R\&D projects within the GNSS industry. Regional Studies, 46(6):741-756.

Balland, P.-A., de Vaan, M., and Boschma, R. A. (2013a). The dynamics of interfirm networks along the industry life cycle: the case of the dynamics of interfirm networks along the industry life cycle: the case of the global video games industry 1987-2007. Journal of Economic Geography, 13 (5): 741-765.

Balland, P.-A., Morrison, A., and Belso-Martínez, J. A. (2013b). The dynamics of technical and business networks in industrial clusters: embeddedness, status or proximity? In 35th DRUID Conference, Barcelona, Spain.

Balland, P.-A., Suire, R., and Vicente, J. (2013c). Structural and geographical patterns of knowledge networks in emerging technological standards: evidence from the European GNSS industry. Economics of Innovation and New Technology, 22(2):47-72.

Barabási, A. and Albert, R. (1999). Emergence of scaling in random networks. Science, 286(5439):509-512.

Barber, M., Heller-Schuh, B., Roediger-Schluga, T., and Scherngell, T. (2008). The Syres EUPRO database manual. Technical report, NEMO Project. 
Bathelt, H. and Glücker, J. (2003). Toward a relational economic geography. Journal of Economic Geography, 3(2):117-144.

Bathelt, H., Malmberg, A., and Maskell, P. (2004). Clusters and knowledge: local buzz, global pipelines and the process of knowledge creation. Progress in Human Geography, 28(1):31-56.

Baum, J., McEvily, B., and Rowley, T. (2012). Better with age? Tie longevity and the performance implications of bridging and closure. Organization Science, 23(2):529- 546.

Boggs, J. and Rantisi, N. (2003). The "relational turn" in economic geography. Journal of Economic Geography, 3(2):109-116.

Borgatti, S. P. and Everett, M. G. (1999). Models of core/periphery structures. Social Networks, 21(4):375-395.

Boschma, R. A. (2005). Proximity and innovation: a critical assessment. Regional Studies, 39(1):61-74.

Boschma, R. A. and ter Wal, A. L. (2007). Knowledge networks and innovative performance in an industrial district: the case of a footwear district in the south of Italy. Industry \& Innovation, 14(2):177-199.

Breschi, S. and Lenzi, C. (2012). Net city: how co-invention networks shape inventive productivity in us cities. In American Association of Geography 2012 Conference, New York, NY.

Broekel, T. and Graf, H. (2012). Public research intensity and the structure of German R\&D networks: a comparison of 10 technologies. Economics of Innovation and New Technology, 21(4):345-372.

Buenstorf, G. and Klepper, S. (2009). Heritage and agglomeration: the Akron tyre cluster revisited. The Economic Journal, 119(537):705-733.

Cattani, G. and Ferriani, S. (2008). A core/periphery perspective on individual creative performance: Social networks and cinematic achievements in the Hollywood film industry. Organization Science, 19(6):824-844.

Cohen, W. M. and Levinthal, D. A. (1990). Absorptive capacity: a new perspective on learning and innovation. Administrative Science Quarterly, 35(1):128-152.

Coleman, J. S. (1988). Social capital in the creation of human capital. American Journal of Sociology, 94:S95-S120.

Crespo, J. (2011). How emergence conditions of technological clusters affect their viability? Theoretical perspectives on cluster life cycles. European Planning Studies, 19(12):20252046.

Crespo, J., Suire, R., and Vicente, J. (2013). Lock-in or lock-out? How structural properties of knowledge networks affect regional resilience. Journal of Economic Geography, forthcoming. doi:10.1093/jeg/lbt006.

Dasgupta, P. and David, P. A. (1994). Toward a new economics of science. Research Policy, 23(5):487 - 521 .

Dunnewijk, T., and Hultén, S. (2007). A brief history of mobile phone communication in Europe. Telematics and Informatics, 24(3):164-179.

Fleming, L., King, C., and Juda, A. I. (2007). Small worlds and regional innovation. Organization Science, 18(6):938-954.

Funk, J. L. (2009). The co-evolution of technology and methods of standard setting: the case of the mobile phone industry. Journal of Evolutionary Economics, 19(1):73-93.

Funk, J. L. (2011). Standards, critical mass, and the formation of complex industries: the case study of mobile Internet. Journal of Engineering and Technology Management, 28(4):232248. 
Giachetti, C. and Marchi, G. (2010). Evolution of firms' product strategy over life cycle of technology-based industries: a case study of the global mobile phone industry, 1980-2009. Business Histoy, 52(7):1123-1150.

Giuliani, E. and Bell, M. (2005). The micro-determinants of meso-level learning and innovation: evidence from a Chilean wine cluster. Research Policy, 34(1):47-68.

Grabher, G. (1993). The weakness of strong ties: the lock-in of regional development in the Ruhr-area. In Grabher, G., editor, The embedded firm: on the socioeconomics of industrial networks, pages 255-278. T.J. Press, London, UK.

Grabher, G. (2002). The project ecology of advertising: tasks, talents and teams. Regional Studies, 36(3):245-262.

Granovetter, M. S. (1985). Economic action and social structure: the problem of embeddedness. American Journal of Sociology, 91(3):481-510.

Gulati, R. and Gargiulo, M. (1999). Where do interorganizational networks come from? American Journal of Sociology, 104(5):1439-1493.

Hervás-Oliver, J. L. and Albors, J. (2012). Are technological gatekeepers constraining my cluster? Unfolding the paradox of gatekeepers resilience across cluster life cycle stages. Papers in Evolutionary Economic Gepgraphy, 12.06.

Jackson, M. O. and Wolinsky, A. (1996). A strategic model of social and economic networks. Journal of Economic Theory, 71(1):44-74.

Jaffe, A. B., Trajtenberg, M., and Henderson, R. M. (1993). Geographic localization of knowledge spillovers as evidenced by patent citations. The Quarterly Journal of Economics, 108(3):577-598.

Klepper, S. (1996). Entry, exit, growth, and innovation over the product life cycle. The American Economic Review, 86(3):562-583.

Klepper, S. (1997). Industry life cycles. Industrial and Corporate Change, 6(1):145-182.

Kogut, B. and Walker, G. (2001). The small world of Germany and the durability of national networks. American Sociological Review, 66(3):317-335.

Koski, H. and Kretchmer, T. (2009). The role of product innovation on the diffusion of mobile telephone. The Research Institute of the Finnish Economy, Discussion Papers 1200.

Koski, H. and Kretchmer, T. (2010). New product development and firm value in mobile handset production. Information Economics and Policy, 22(1):42-50.

Lobo, J. and Strumsky, D. (2008). Metropolitan patenting, inventor agglomeration and social networks: a tale of two effects. Journal of Urban Economics, 63(3):871 - 884.

Madhavan, R., Koka, B. R., and Prescott, J. E. (1998). Networks in transition: how industry events (re)shape interfirm relationships. Strategic Management Journal, 19(5):439-459.

Markusen, A. (1996). Sticky places in slippery space: a typology of industrial districts. Economic Geography, 72(3):293-313.

Marshall, A. (1890). Principles of Economics. Macmillan.

Martin, P., Mayer, T., and Mayneris, F. (2013). Are clusters more resilient in crises? Evidence from French exporters in 2008-2009. CEPR Discussion Paper No. DP9667

Martin, R. and Sunley, P. (2003). Deconstructing clusters: chaotic concept or policy panacea? Journal of Economic Geography, 3(1):5-35.

Menzel, M. P. and Fornahl, D. (2010). Cluster life cycles-dimensions and rationales of cluster evolution. Industrial and Corporate Change, 19(1):205-238.

Mitchell, W. and Singh, K. (1996). Survival of businesses using collaborative relationships to commercialize complex goods. Strategic Management Journal, 17(3):169-195.

Moore, G. (1991). Crossing the chasm. Harper Business Essentials, New York, NY. 
Morrison, A. (2008). Gatekeepers of knowledge within industrial districts: who they are, how they interact. Regional Studies, 42(6):817 - 835.

Newman, M. E. (2000). Models of the small world. Journal of Statistical Physics, 101(34):819-841.

Nooteboom, B. (2000). Learning by interaction: absorptive capacity, cognitive distance and governance. Journal of Management and Governance, 4(1):69-92.

Orsenigo, L., Pammolli, F., Riccaboni, M., Bonaccorsi, A., and Turchetti, G. (1998). The evolution of knowledge and the dynamics of industry network. Journal of Management and Governance, 1:147-175.

Owen-Smith, J. and Powell, W. W. (2004). Knowledge networks as channels and conduits: the effects of spillovers in the Boston biotechnology community. Organization Science, 15(1):5-21.

Porter, M. E. (1998). Clusters and the new economics of competition. Harvard Business Review, 76(6):77-90.

Pouder, R. and John, C. H. S. (1996). Hot spots and blind spots: geographical clusters of firms and innovation. The Academy of Management Review, 21(4):1192-1225.

Rivera, M. T., Soderstrom, S. S., and Uzzi, B. (2010). Dynamics of dyads in social networks: assortative, relational and proximity mechanisms. Annual Review of Sociology, 36:91-115.

Scherngell, T. and Barber, M. (2011). Distinct spatial characteristics of industrial and public research collaborations: evidence from the fifth EU Framework Programme. The Annals of Regional Science, 46(2):247-266.

Schilling, M. A. and Phelps, C. C. (2007). Interfirm collaboration networks: the impact of large-scale network structure on firm innovation. Management Science, 53(7):1113- 1126.

Sorenson, O., Rivkin, J. W., and Fleming, L. (2006). Complexity, networks and knowledge flow. Research Policy, 35(7):994-1017.

Storper, M. and Venables, A. J. (2004). Buzz: face-to-face contact and the urban economy. Journal of Economic Geography, 4(4):351-370.

Suire R., and Vicente, J. (2009). Why Do Some Places Succeed When Others Decline? A Social Interaction Model of Cluster Viability. Journal of Economic Geography, 9(3): 381404.

ter Wal, A. L. and Boschma, R. A. (2011). Co-evolution of firms, industries and networks in space. Regional Studies, 45(7):919-933.

Tushman, M. and Murmann, J. P. (1997). Dominant designs, technology cycles, and organizational outcomes. In Garud, R., Kumaraswamy, A., and Langlois, R. N., editors, Managing in the modular age, pages 316-361. Blackwell Publisher.

Utterback, J. M. and Suárez, F. F. (1993). Innovation, competition, and industry structure. Research Policy, 22(1):1-21.

Uzzi, B. (1997). Social structure and competition in interfirm networks: the paradox of embeddedness. Administrative Science Quarterly, 42(1):35-67.

Uzzi, B. and Spiro, J. (2005). Collaboration and creativity: the small world problem. American Journal of Sociology, 111(2):447-504.

Vicente, J., Balland, P.-A., and Brossard, O. (2011). Getting into networks and clusters: evidence on the GNSS composite knowledge process in (and from) Midi-Pyrénées. Regional Studies, 45(8):1059-1078.

Watts, D. J. and Strogatz, S. H. (1998). Collective dynamics of 'small-world' networks. Nature, 393(6684):440-442. 